\title{
Assessing creativity in design education: Analysis of creativity factors in the first-year design studio
}

Halime Demirkan and Yasemin Afacan, Department of Interior Architecture and Environmental Design, Faculty of Art, Design and Architecture, Bilkent University, 06800 Bilkent, Ankara, Turkey

The aim of this study is to explore creativity in design education and identify the creativity assessment indicators in the first-year design studio. A measurement tool of 41 items that consists of the artifact creativity, design elements and assembly of design elements were utilised for the assessment of 210 artifacts. Results of the exploratory and confirmatory factor analysis indicated three main design creativity factors. The primary factor consists of the novelty and affective characteristics of artifact that are associated with its shape. The second factor has the elaboration characteristics that are integrated with its geometric and figure-ground relations and harmony of design elements. The third factor consists of rhythm, repetition, unity, order and number of design elements.

(c) 2011 Elsevier Ltd. All rights reserved.

Keywords: Creative design, Creativity, Design education, Design process, Evaluation

Corresponding author: Halime Demirkan demirkan@bilkent. edu.tr

\begin{abstract}
$\mathrm{C}$ reativity as a natural component of design process has often been characterised by the 'creative leap' that occurs between problem and solution space (Demirkan, 2010). Since the nature of creativity is so complex, there is no single definition that fully encompasses this concept and identifies a solution as creative. So, there can be no guarantee that a creative 'event' will occur during a design process (Dorst \& Cross, 2001). In design education, various assessment methods were always discussed and instruments were devised (Demirbas \& Demirkan, 2003). Although assessment of creativity is considered as an important issue in the design education, there is a limited number of creativity researches conducted in the design domain. Christiaans and Venselaar (2005) pointed the difficulties of making creativity research in design process by referring to the interference of concurrent protocol analysis on the cognitive processes of designers. Also, they stated another difficulty as the absence of specific assessment technique for measuring creativity of designers. These difficulties are a consequence related to the nature of design process. In design process, a designer constructs a conceptual model of the artifact by abstracting knowledge from the previous experiences and information stored in the memory. These conceptual representations are linked with both the external forms of knowledge
\end{abstract}

\section{www.elsevier.com/locate/destud}

0142-694X S - see front matter Design Studies 33 (2012) 262-278

doi:10.1016/j.destud.2011.11.005

(C) 2011 Elsevier Ltd. All rights reserved. 
and the internal representations of the model. Drawings and sketches are considered as the externalisation of images (Demirkan, 1998). These could be considered as the products of the design process.

\section{An overview of creativity in the design context}

"In architectural design process the interaction between person, creative process and creative product inside a creative environment should be considered as a total act in assessing creativity" (Demirkan, 2010, p. 58). Although these four elements of creativity were claimed to act together, there are studies that focus on each element or interactions between them. There have been previous attempts to understand the creative personal traits of designers (Candy \& Edmonds, 1996; Cross, 2002; Lawson, 1994). Akin and Akin (1998) analysed the cognitive processes of designers in their activities and found that there were also similar acts in the other art fields such as music, painting and sculpture. This founding was also supported by Christiaans (2002) study where also he stated that there is no difference in the judgement of experts and non-experts of design field.

Over the past years, some researchers investigated the creative processes to develop a better understanding of how creative design occurs and tried to determine its relationship with the creative product development (Roy, 1993). Later, Hennessey (1994) tried to find the fundamental criteria in the assessment procedures of product creativity. Christiaans and Venselaar (2005) found a high correlation between amount of process knowledge and creativity of the product.

Hasirci and Demirkan (2003) focused on the interaction between person, process and product inside a creative environment, namely two sixth grade artrooms. They found that the three elements of creativity (person, process and product) were significantly different from each other. Later, these three elements of creativity were investigated deeply by focussing on the cognitive stages of the creative decision making process in a design studio (Hasirci \& Demirkan, 2007). They used observation, protocol analysis and rating scales as tools of assessment. While observation was used during the creative design process, the latter two were carried out after the design process. It was found that the highest correlation was between process and overall creativity.

In the creativity literature, there are many studies that analyse whether there exists an interrelation between person, process and product elements of design creativity. In the previous studies of Hasirci and Demirkan (2003, 2007), person, process and product were considered as independent elements of creativity. Furthermore, to redefine the elements of creativity from a new perspective, the overall factors and the interactions among the elements were analysed within the design domain (Demirkan \& Hasirci, 2009). The main finding of this study was that the product element is the strongest factor $(45.85 \%)$ in de- 
termining the amount of creativity in design process. The second $(19.54 \%)$ and third factors $(14.46 \%)$ both consist of person and process elements.

Casakin and Kreitler (2008) focused on the correspondences and divergences between instructors and students for assessing creativity in the design studio. Later, they tested the validity of self-perceived creativity as the measure of creativity (Kreitler \& Casakin, 2009, 2010). Among the nine creativity indicators (fluency, flexibility, elaboration, functionality, innovation, fulfilling design requirements, considering context, mastery of skills related to aesthetics in representation and overall creativity), only three indicators (fluency, flexibility and overall creativity) were found to be positive and significant.

Dorst and Cross (2001) claimed that "[s]tudying creative design is seen as problematic because there can be no guarantee that a creative 'event' will occur during a design process, and because of the difficulty of identifying a solution idea as 'creative'. However, in every design project creativity can be found" (p.426). In the literature, there are other studies that investigated the composition of product creativity by analysing the elements of product creativity from the perspective of consumers (Horn \& Salvendy, 2006, 2009). They constructed a conceptual product creativity assessment model within the context of information processing model. As a result, they identified six product creativity factors; resolution, emotion, centrality, importance, desire and novelty. In this model, comprehension of product creativity is limited to the expert's experience with the product functions as well as understanding of functionality within the scope of visual perception. Later, the model was tested on the web-based evaluations of chairs and lamps and also with the paper based evaluations (Horn \& Salvendy, 2009). The previously stated six product creativity factors were refined by conducting the exploratory factor analyses that resulted in three main product creativity factors; affect, importance and novelty that explained $72 \%$ of the common variance. This study showed the factors of product creativity from the consumer perception of product within the context of satisfaction and purchasability.

Based on the previous research involving creativity, product development and design, this study defines design creativity as the conceptual judgement of the design instructors. Mostly in the design literature, a product is defined as a finalised three dimensional object. However, in the design process, the final drawing is considered as the final product. In order to differentiate it from the three dimensional product, it will be referred as 'artifact' within the study.

Based on the previous studies in the literature that found product as the powerful element of creativity in design domain (Demirkan \& Hasirci, 2009; Horn $\&$ Salvendy, 2009), this study focuses on the artifact (in terms of product) element of creativity. Furthermore, it is intended to refine and integrate the artifact creativity with the characteristics and principles of design elements. Also, 
the creativity assessment tool that can be used for identifying the factors in the artifact creativity was developed and tested for its internal validity. The developed tool that was composed of three factor model was further tested for its stability with a maximum likelihood confirmatory factor analysis.

\section{Model}

Based on the previous research involving creativity in design products, the dimensions of creativity are named as the artifact creativity, the design elements and the assembly of design elements. In the creativity literature, it is found that these issues are examined independently and the interactions among them are not investigated. This study tries to itemise each dimension and delves deeper by analysing the interactions among these dimensions. To be a creative design product, the artifact should have certain characteristics of creativity (items) in terms of novelty (new, novel, unusual, unconventional, unique, original, infrequent, extraordinary, different, eccentric and exciting), elaboration (integrated, polished, refined, adequate, deliberate, detailed, sensible, balanced and coherent) and affective aspects (appealed, delighted, good and pleasant). An expert in the field of design creativity can assess the creativity characteristics of an artifact. This study is based on the previous study that has identified certain characteristics of the artifact creativity (Hasirci \& Demirkan, 2007). Also, the literature related to the product creativity has been studied (Besemer \& Treffinger, 1981; Besemer, 1998; Christiaans, 2002; Demirkan \& Hasirci, 2009; Hasirci \& Demirkan, 2003; O'Quin \& Besemer, 1999, 2006; Runco, 2004; Simonton, 2003), in order to obtain certain measurements of creativity that fit to the artifact assessment.

According to art, architecture and design educators, there is a need for a formal visual language, which is formalised and clarified by basic principles of design, to attain a degree of originality in the cognitive, affective and psychomotor domains of creativity (Wallschlaeger \& Busic-Snyder, 1992). In Demirkan and Hasirci's (2009) study, basic principles of design that are the design elements and the assembly of design elements were also considered as the hidden dimensions of creativity. The design elements were defined as the characteristics of design that are important in creating a pattern and listed as shape/form, colour, space, line value and texture. Furthermore, the way design elements come together were called as the assembly of design elements that were listed as harmony, emphasis, rhythm, unity, variety, repetition and balance.

In this study, shape, size, number, proportion, geometric relations, figureground relation and colour are considered as the design elements. Shape is defined as "the outline or contour of an element" (Olgunturk \& Demirkan, 2011, p. 271). For this study, the subjects were restricted to use regular geometric shapes; square, triangle and circle and their derivatives. Size is how small or large is an element or group of elements and number is the quantity of elements. Proportion is the relationship between parts of the elements with respect to magnitude, quantity or degree (Ching, 2007). The way the geometries connect 
one to another is called the geometric relationship. Figure-ground relationship is the relationship between the design figures (parts of composition) and background information (design field) that is the paper in this artifact. "Colour is a sensation produced by visible electromagnetic radiation (light) that stimulates receptors in our eyes" (Olgunturk \& Demirkan, 2011, p. 271).

Assembly of design elements is an act that can be repeatedly, variably and dependably done with elements to produce some sort of visual effect in a design field. In this study, the assembly of design elements involves harmony, rhythm, unity, variety, repetition, balance and order. Harmony brings together a composition with similar design elements. Rhythm is achieved through the orderly repetition of any design element. Unity is the way individual elements of the design relate to each other and to the total design. Variety can be achieved when certain characteristics of the elements are changed. As an example, repeating a similar shape but changing the size can give variety. Repetition is the use of the same design elements without any change. Balance is the consideration of visual weight and importance of design elements with respect to the design field. The relationship of grouping or placing design elements is called order (Arnheim, 1977; Ching, 2007).

The aim of the study is to determine the items that can be evaluated as the characteristics of design creativity for assessing it in design education. Furthermore, it intends to explore the interaction among the artifact creativity, the design elements and the assembly of design elements with the use of exploratory and confirmatory factor analyses.

\section{Methodology}

\subsection{Participants and artifact}

The sample was comprised of 210 first-year design students of the Department of Interior Architecture and Environmental Design at Bilkent University. Seventy-nine percent $(n=166)$ of the subjects were female.

Firstly, the subjects were asked to choose a pattern from nature. Then, they had to analyse carefully the structure and geometric shapes of the selected pattern. Based on this analysis, then they should make an abstraction of the selected natural pattern. The subjects were asked to design an artifact inspired from nature consisting of regular geometries and then to colour it. Artifact in Figure 1 is inspired from a leaf and in Figure 2 from the trunk of a tree.

\subsection{Assessment tool}

The design creativity assessment tool consists of the individual assessments of the artifact creativity, the design elements and the assembly of design elements dimensions. Based on the review and appraisal of the literature on product/artifact creativity and experience on the creativity rating scales, 31 items were determined as the characteristics of artifact creativity. Also, 8 items as the design 
Figure 1 Artifact example (Factor $1=43$ points; Factor $2=35$ points and Factor $3=16$ points).

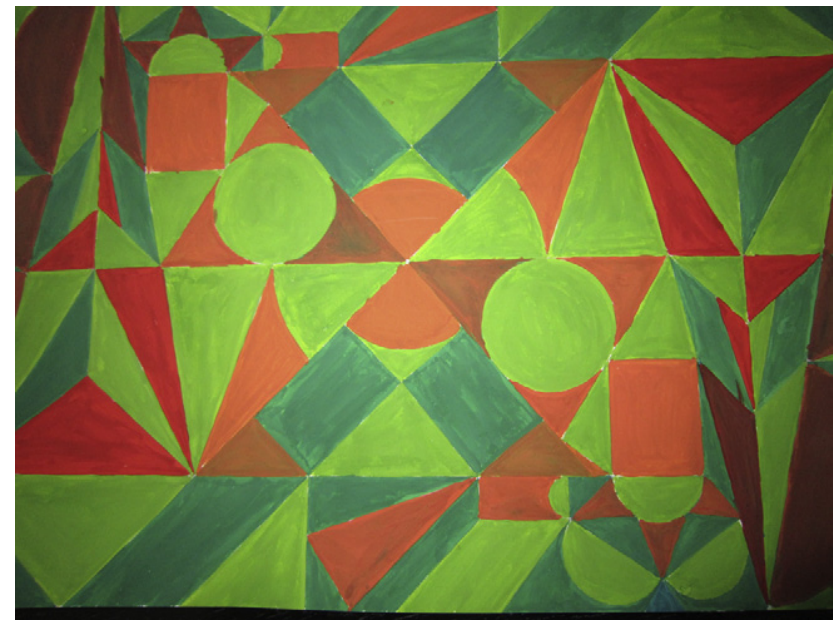

elements and 10 items as the assembly of design elements were decided. Two experts within the field were asked to mark each item on a 5-point Likert scale ( $1=$ poor; $2=$ poor-average; $3=$ average; $4=$ average-excellent $5=$ excellent $)$. Expert one has 32 years of experience in design discipline and involved with the creativity studies more than 20 years. Expert two has 10 years of experience in the design field and a well-trained rater. Besides having experienced raters, this study is based on the literature that reports the relevant scientific information for the calculation of a confidence interval for intra-class correlation to assess the inter-rater reliability of the studies (Shoukri, Asyali, \& Donner, 2004). Since there were 210 first-year design students as subjects, two raters were providing an acceptable level of reliability for the assessment of the creativity tool. With the sample size of 210 and 2 raters, the variance of the estimated intra-class correlation coefficient was minimised.

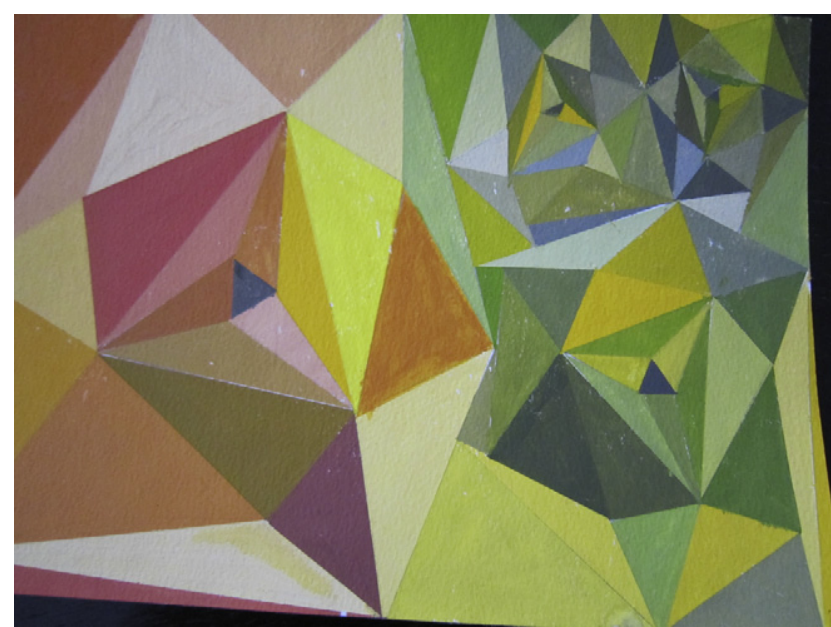

Figure 2 Artifact example (Factor $1=37$ points; Factor $2=18$ points and Factor $3=9$ points) . 
Initially to verify the appropriateness and stability of the instrument, a pilot study was conducted with a small sample. The overall internal consistency was verified to insure the consistency of the assessments $(\alpha=0.967, n=49$ items). After the pilot study, some items that do not match with the artifact were eliminated. The rating scale was refined by eliminating 4 items from the artifact creativity, 1 item from the design elements and 3 items from the assembly of design elements that do not apply to this specific artifact. Total of 41 items were kept at the final rating scale (Table 1).

The first dimension measures the artifact characteristics that are associated with creativity. These items are based on the previous studies in the literature on the product creativity (Besemer \& Treffinger, 1981; Besemer, 1998; Christiaans, 2002; Horn \& Salvendy, 2006, 2009; O'Quin \& Besemer, 1999, 2006) and the artifact creativity (Demirkan \& Hasirci, 2009; Hasirci \& Demirkan, 2003, 2007). The second and third dimensions are the design elements and the assembly of design elements that are important issues in creating designs and they are substantial values in the design process. In the previous studies, these items were assessed as the independent items of creativity and evaluated within their own group without considering their interactions (Demirkan \& Hasirci, 2009; Hasirci \& Demirkan, 2003, 2007). This study goes further and tries to find out how these items can be integrated in the assessment of design creativity.

The assessment was done with 41 items by the two experts independently; thus the possibility of affecting each other while assessing the artifacts were eliminated. The raw averages of the two scores were calculated for the final scores. The first aim of the study was to evaluate the measurement model by using the exploratory factor analysis and after to evaluate the structural model of the study by using the confirmatory factor analysis. All data analysis was performed using SPSS version 15.0 and LISREL 8.8 (Joreskog \& Sorbom, 2011) for the confirmatory factor analysis.

\section{Results}

\subsection{Exploratory factor analysis of design creativity}

An examination of the descriptive statistics and internal validity of the rating scale items was conducted. The mean scores for the design creativity items

Table 1 Dimensions and related items of design creativity assessment tool

\begin{tabular}{ll}
\hline Design creativity dimension & \multicolumn{1}{c}{ Measurement items } \\
\hline Artifact creativity & $\begin{array}{l}\text { Integrated, coherent, detailed, refined deliberate, polished, balanced, } \\
\text { significant, adequate, sensible, different, unconventional, infrequent, } \\
\text { extraordinary, exciting, zippy, fresh, eccentric, new, novel, unusual, } \\
\text { unique, original, pleasant, good, delighted, appealed }\end{array}$ \\
Sesign elements & $\begin{array}{l}\text { Shape, colour, size, proportion, number, geometric relations, } \\
\text { figure-ground relation }\end{array}$ \\
Assembly of design elements & Harmony, rhythm, unity, variety, repetition, balance, order \\
\hline
\end{tabular}


ranged from 2.44 to 3.50 with standard deviation from 1.13 to 3.17. Cronbach's Alpha for each of the 41 items ranged from 0.967 to 0.974 , indicating satisfactory internal consistency.

In order to determine the factors of design creativity, maximum likelihood factor analysis was conducted. Initially, 5 factors had eigenvalues equal to or greater than 1.00 with the explained variance $67.5 \%$. Among the 5 factors, 3 of them had at least 3 items and the rest had less, thus, these 3 factors were considered in this study. These 3 factors accounted for the $62.3 \%$ of the variance as seen in Table 2 .

The maximum likelihood extraction method is used $\left(\chi^{2}=1417.12, \mathrm{df}=625\right.$, $p<0.001)$. An orthogonal factor rotation was performed using the Varimax with Kaiser Normalisation. According to Tabachnick and Fidell (1996), the item's pure measure of the factor increases with greater loading. Items that had relationships $50 \%$ and above with the factor were thought to describe the factor and its related scale the best, thus those items would provide the best assessment for the particular case. Therefore, 16 items that had loadings above 0.50 were eligible items in describing the first factor (Table 3 ).

It is found that the primary factor, which was responsible of $50.2 \%$ of the total variance, is composed 16 items that are associated with the novelty characteristics (new, novel, unusual, unconventional, unique, original, infrequent, extraordinary, different, eccentric and exciting) and the affective characteristics (appealed, delighted, good and pleasant) of the artifact as well as its shape. The second factor, which was responsible of $9.3 \%$ of total variance, has 12 items that are associated with the elaboration characteristics (integrated, polished, refined, adequate, deliberate, detailed, sensible, balanced and coherent) of the artifact as well as with the geometric, figure-ground relations and harmony of the design elements. The third factor, which was responsible of $2.8 \%$ of the total variance, consists of 5 items as rhythm, repetition, unity and order and number of the design elements.

\subsection{Confirmatory factor analysis of design creativity}

The three factor model was further tested for stability with the maximum likelihood confirmatory factor analysis using LISREL 8.8 (Joreskog \& Sorbom,

Table 2 Summary of rotated factors

\begin{tabular}{lllll}
\hline Factor & \multicolumn{1}{c}{ Items (in decreasing loadings) } & Eigen-value & Var. (\%) & Cum.(\%) \\
\hline 1 & $\begin{array}{l}\text { New, Novel, Unusual, Unconventional, Unique, Original, } \\
\text { Infrequent, Extraordinary, Different, Eccentric, Appealed, }\end{array}$ & 21.73 & 50.17 & 50.17 \\
& $\begin{array}{l}\text { Delighted, Exciting, Good, Pleasant, Shape } \\
\text { Integrated, Polished, Refined, Adequate, Deliberate, } \\
\text { Geometric, Detailed, Figure-ground, Sensible, Balanced, } \\
\text { Coherent, Harmony } \text {, }\end{array}$ & 3.85 & 9.32 & 59.49 \\
3 & Rhythm, Repetition, Number, Unity, Order & 1.82 & 2.79 & 62.28 \\
\hline
\end{tabular}




\begin{tabular}{|c|c|c|c|c|c|}
\hline & \multicolumn{5}{|c|}{ Factor } \\
\hline & 1 & 2 & 3 & 4 & 5 \\
\hline New & 0.892 & 0.226 & 0.179 & 0.120 & -0.264 \\
\hline Novel & 0.872 & 0.233 & 0.199 & 0.163 & -0.279 \\
\hline Unusual & 0.854 & 0.224 & 0.119 & 0.159 & -0.135 \\
\hline Unconventional & 0.851 & 0.215 & 0.110 & 0.041 & 0.240 \\
\hline Unique & 0.846 & 0.193 & 0.152 & 0.148 & -0.059 \\
\hline Original & 0.840 & 0.227 & 0.186 & 0.202 & -0.099 \\
\hline Infrequent & 0.834 & 0.257 & 0.169 & 0.075 & 0.164 \\
\hline Extraordinary & 0.804 & 0.233 & 0.045 & 0.049 & 0.214 \\
\hline Different & 0.780 & 0.337 & 0.128 & 0.134 & 0.235 \\
\hline Eccentric & 0.771 & 0.157 & 0.169 & 0.138 & 0.016 \\
\hline Appealed & 0.641 & 0.371 & 0.206 & 0.594 & -0.027 \\
\hline Delighted & 0.626 & 0.384 & 0.216 & 0.604 & -0.020 \\
\hline Exciting & 0.609 & 0.448 & 0.177 & 0.300 & 0.097 \\
\hline Good & 0.609 & 0.407 & 0.267 & 0.513 & -0.033 \\
\hline Pleasant & 0.596 & 0.394 & 0.233 & 0.529 & -0.068 \\
\hline Shape & 0.555 & 0.481 & 0.292 & 0.213 & -0.055 \\
\hline Fresh & 0.485 & 0.434 & 0.180 & 0.349 & 0.041 \\
\hline Zippy & 0.421 & 0.420 & 0.175 & 0.371 & 0.129 \\
\hline Variety & 0.415 & 0.332 & -0.049 & 0.021 & -0.086 \\
\hline Integrated & 0.213 & 0.765 & 0.327 & 0.057 & 0.024 \\
\hline Polished & 0.417 & 0.742 & 0.037 & 0.172 & 0.073 \\
\hline Refined & 0.407 & 0.735 & 0.198 & 0.173 & 0.037 \\
\hline Adequate & 0.420 & 0.698 & 0.274 & 0.182 & 0.071 \\
\hline Deliberate & 0.441 & 0.682 & 0.208 & 0.084 & 0.087 \\
\hline Geometric & 0.153 & 0.666 & 0.312 & 0.141 & -0.085 \\
\hline Detailed & 0.446 & 0.660 & 0.235 & 0.170 & 0.036 \\
\hline Figure-ground & 0.113 & 0.605 & 0.180 & 0.087 & -0.048 \\
\hline Sensible & 0.443 & 0.596 & 0.361 & 0.194 & 0.144 \\
\hline Balanced & 0.014 & 0.550 & 0.403 & 0.116 & -0.056 \\
\hline Coherent & 0.256 & 0.536 & 0.501 & 0.093 & 0.046 \\
\hline Harmony & 0.361 & 0.525 & 0.489 & 0.284 & -0.029 \\
\hline Proportion & 0.307 & 0.493 & 0.412 & 0.160 & -0.116 \\
\hline Size & 0.418 & 0.466 & 0.402 & 0.088 & -0.026 \\
\hline Significant & 0.264 & 0.446 & 0.131 & 0.096 & -0.018 \\
\hline Colour & 0.364 & 0.371 & 0.235 & 0.274 & -0.006 \\
\hline Rhythm & 0.118 & 0.207 & 0.880 & 0.113 & 0.058 \\
\hline Repetition & 0.159 & 0.160 & 0.675 & 0.151 & 0.087 \\
\hline Number & 0.405 & 0.183 & 0.655 & 0.194 & 0.048 \\
\hline Unity & -0.010 & 0.470 & 0.618 & 0.061 & -0.043 \\
\hline Order & 0.081 & 0.111 & 0.505 & 0.008 & -0.174 \\
\hline Balance & 0.009 & 0.219 & 0.293 & -0.048 & 0.088 \\
\hline
\end{tabular}

Extraction method: maximum likelihood. Rotation method: Varimax with Kaiser Normalisation (rotation converged in 7 iterations).

2011). The model had $\chi^{2}=6355.33(\mathrm{df}=776, p<0.001)$. The goodness of fit statistic based on the covariance matrix of the remaining items, was rather low (goodness of fit index $=0.403$, adjusted goodness of fit index $=0.337$ ). As Kunnan (1998) claimed that if "other goodness of fit (GFI) indices, generally formulated to range in value 0 (no model fit) to 1.0 (perfect model fit) that should be consulted in addition to $\chi^{2}$ statistic include: comparative fit index 
(CFI) or the goodness of fit index (GFI) [...]. Generally, if any of these indices are above 0.90 , the rule of thumb is that there is recommendation from the indices there is model fit, pending examination of the $\chi^{2}$ statistic and model interpretability" (p. 307). An index value between 0.90 and 0.95 is acceptable and above 0.95 is good. The model proved acceptable based on the following statistical tests including; normed-fit index $(\mathrm{NFI})=0.92$, non-normed-fit index $(\mathrm{NNFI})=0.93$, parsimony normed-fit index $(\mathrm{PNFI})=0.87$, comparative fit index $(\mathrm{CFI})=0.94$, incremental fit index $(\mathrm{IFI})=0.94$, relative fit index $(\mathrm{RFI})=0.92$. Therefore, since NFI, NNFI, CFI and IFI are above 0.90 , it can be concluded that there is model fit.

Hatcher (1996) stated that for a model to provide an ideal fit, the $p$ value associated with the model fit $\chi^{2}$ test should exceed 0.05 and being closer to 1.00 is better. Since $p<0.001$ in this model, it can be assumed that there is no ideal fit for this study. But Saris, Satorra, and Sorbom (1987) found that the $\chi^{2}$ statistic is acceptable only for the large samples. The sample size in this study is 210 . Bentler and Chou (1987) suggested five subjects per item and Kunnan (1998) said "that sample sizes less than 150 may not ensure stable estimates or for that matter representativeness" (p. 300). Therefore, since the developed instrument having 41 items, 205 samples is the minimum amount recommended for the application of the statistical techniques. The path diagram of the model can be seen in Figure 3.

The structural equation model is used for a plausible explanation of the relations between the artifact creativity, the design elements and the assembly of design elements. The model shows how 41 items (observed variables) are related to the 3 latent variables (see Figure 3 ). The artifact creativity (exogenous variable) has a high regression coefficient $(\gamma=0.85)$ of the design elements and there is a negative low regression coefficient $(\gamma=-0.21)$ of the assembly of design elements. The structural error term $(\zeta=1.04)$ shows how the design elements and the assembly of design elements share a common variation and the predictor relations in the model do not explain it.

As seen in Figure 3, the loadings $(\lambda)$ of the creativity elements range from 0.51 to 1.13 with the lowest being balance and the highest being original. The loadings $(\lambda)$ of the design elements range from 0.78 to 1.08 with the lowest being colour and the highest being number. The loadings $(\lambda)$ of the assembly of design elements range from 0.36 to 1.14 with the lowest being variety and the highest being rhythm.

\subsection{Predictive validity of the design creativity rating scale}

Further analysis was done for testing the validity of the rating scale. The predictive analysis was examined with the squared multiple correlation for each variable in the model. It is the percent variance explained for each variable. LISREL output gives the squared multiple correlations for each variable in Table 4. 


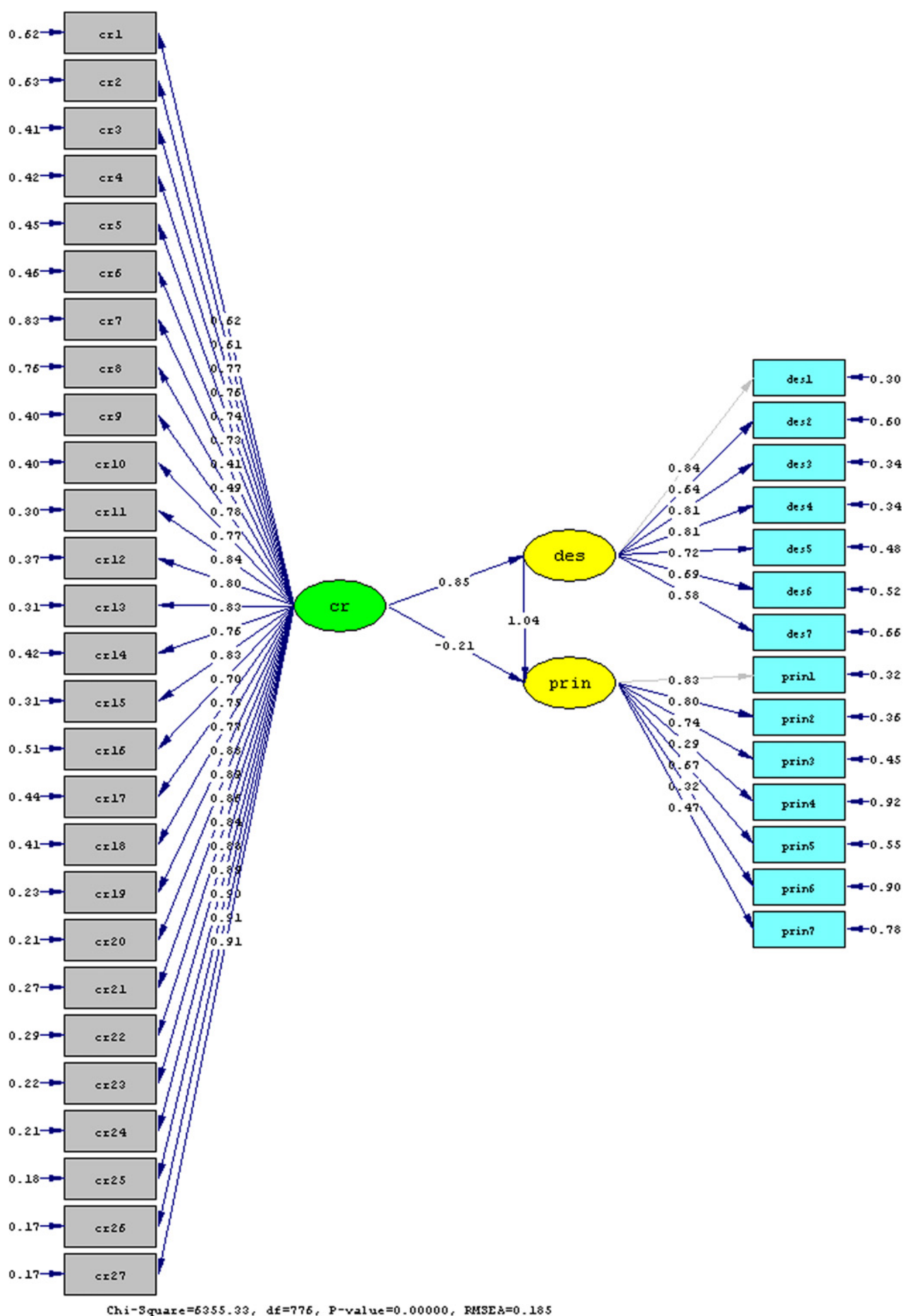

Figure 3 Standardised LISREL estimates of design creativity model $\left(\chi^{2}=6355.33, d f=776, \mathrm{p}<0.001 ;\right.$ cr $=$ artifact creativity; des $=$ design elements; prin = assembly of design elements) 
Table 4 Prediction of design creativity elements from squared multiple regression model

\begin{tabular}{|c|c|c|c|c|c|}
\hline \multicolumn{2}{|c|}{$\mathrm{R}^{2}-$ design elements (des) } & \multicolumn{2}{|c|}{$\mathrm{R}^{2}-$ assembly of design elements (prin) } & \multicolumn{2}{|c|}{$\mathrm{R}^{2}-$ artifact creativity (cr) } \\
\hline 1. Shape & 0.699 & 1. Harmony & 0.684 & 1. Integrated & 0.382 \\
\hline 2. Colour & 0.404 & 2. Rhythm & 0.640 & 2. Coherent & 0.369 \\
\hline 3. Size & 0.663 & 3. Unity & 0.545 & 3. Detailed & 0.592 \\
\hline 4. Proportion & 0.663 & 4. Variety & 0.084 & 4. Refined & 0.580 \\
\hline 5. Number & 0.521 & 5. Repetition & 0.450 & 5. Deliberate & 0.548 \\
\hline 6. Geometric & 0.480 & 6. Balance & 0.100 & 6. Polished & 0.535 \\
\hline \multirow[t]{21}{*}{ 7. Figure-ground } & 0.340 & 7. Order & 0.220 & 7. Balanced & 0.166 \\
\hline & & & & 8. Significant & 0.239 \\
\hline & & & & 9. Adequate & 0.604 \\
\hline & & & & 10. Sensible & 0.598 \\
\hline & & & & 11. Different & 0.698 \\
\hline & & & & 12. Unconventional & 0.635 \\
\hline & & & & 13. Infrequent & 0.694 \\
\hline & & & & 14. Extraordinary & 0.575 \\
\hline & & & & 15. Exciting & 0.692 \\
\hline & & & & 16. Zippy & 0.491 \\
\hline & & & & 17. Fresh & 0.561 \\
\hline & & & & 18. Eccentric & 0.592 \\
\hline & & & & 19. New & 0.774 \\
\hline & & & & 20. Novel & 0.778 \\
\hline & & & & 21. Unusual & 0.731 \\
\hline & & & & 22. Unique & 0.713 \\
\hline & & & & 23. Original & 0.776 \\
\hline & & & & 24. Pleasant & 0.786 \\
\hline & & & & 25. Good & 0.817 \\
\hline & & & & 26. Delighted & 0.831 \\
\hline & & & & 27. Appealed & 0.829 \\
\hline
\end{tabular}

In the design elements highest correlation belongs to shape, in the assembly of design elements to harmony and in the artifact creativity to delighted artifact. Among all the items, the lowest value belongs to balance in the assembly of design elements and followed by balanced in the artifact creativity. The correlation between the artifact creativity and the design elements is high $(r=0.848)$ and the artifact creativity and the assembly of design elements is medium $(r=0.673)$.

\section{Discussion}

\subsection{On the exploratory factor analysis}

Three factors were found by the exploratory factor analysis. Among 16 items of the first factor, only one item belongs to the design elements and the others all belong to the artifact creativity (Table 3 ). The first 10 items ranking from the highest to the lowest loadings are the 'novelty characteristics' of the artifact. These are namely new, novel, unusual, unconventional, unique, original, infrequent, extraordinary, different and eccentric. "Novelty depicts that the quality of something being new and unusual for the student and at that level of education" (Demirkan \& Hasirci, 2009, p. 298). Then, the first factor involves appealed, delighted, exciting, good and, pleasant characteristics of 
the artifact. These items can be named as the 'affective characteristics' of the artifact and could be thought as feelings or mood associated with a particular artifact (Olgunturk \& Demirkan, 2011). So, the artifact characteristic is providing an affective interaction with the assessor. This is not a cognitive interaction as the novelty provides. Shape is the only design element that is associated with the affective artifact characteristics. Therefore, factor 1 is named as the 'novelty and affective characteristics' of the artifact (Table 2). Then, fresh, zippy and variety are listed (Table 3). These are not considered in the first factor since they have lower than 0.50 loadings.

The second factor involves 12 items. Among 12, 9 items belong to the artifact creativity, 2 items to the design element and 1 to the assembly of design elements (Table 3). The artifact creativity items are integrated, polished, refined, adequate, deliberate, detailed, sensible, balanced and coherent. These characteristics involve the elaboration of the artifact. Therefore, it is named as 'elaboration characteristics' of the artifact (Table 2). This factor can be explained as the variety of implications that a designer produces. The geometric relations of the elements and the figure-ground relations both provide and increase in the elaboration characteristics of the artifact. Harmony, also as a tool to assemble the design elements, adds to the elaboration value of the artifact. Following 3 design elements (proportion, size and colour) and 1 artifact creativity item (significant) are not considered with their low loadings (Table 3).

The third factor involves 5 items (Table 3). Among 5, 4 items belong to the assembly of design elements and one item to the design elements. Rhythm, repetition, unity and order are the assembly of design elements and number belongs to the design elements. This factor is named as 'design principles' (Table 2).

Empirical research on the product creativity mostly investigated creativity through the products that are the consequences of creative process (Besemer, 1998; Hennessey, 1994; Christiaans \& Venselaar, 2005; Dorst \& Cross, 2001; Krueger \& Cross, 2006). Within the context of architectural design process, self-perceived creativity as a measure of creativity was also examined (Casakin \& Kreitler, 2008; Kreitler \& Casakin, 2009, 2010). Fluency, flexibility and overall creativity were found as the three indicators of architectural design process.

Similar to this study, Horn and Salvendy (2009) tested the web-based evaluations of chairs and lamps. Their study resulted in three main product creativity factors as affect, importance and novelty. In this study, the first factor that is related to the creative design characteristics consists of the novelty and affective characteristics of the artifact. These characteristics are dependent on the cognitive and affective perception of the human being who rates the artifact as an expert. This study complies with Horn and Salvendy's (2009) study 
but it differs by further highlighting that the design product (artifact) has creative characteristics that depend on the cognitive and affective perception of the person who assesses it.

This study explores as a pioneer the relationship between creativity and design characteristics. Shape is found to be the only design element that belongs to the cognitive and affective artifact characteristics. Shape was found to be the internal design element with the highest loading (0.988) in Demirkan and Hasirci's (2009) study. Since they examined independently each factor characteristic, the interaction of shape with the creative product characteristics was not found. In this study, the geometric relations of the elements, figure-ground relations and harmony provide and increase in the elaboration characteristics of the artifact. Figure-ground relationship is the inter-dependence between the elements of a design and the design field. In designs, instead of a distinction between the foreground and background, an unbroken sequence of shape and colour is preferred (Arnheim, 1969). In Olgunturk and Demirkan's (2011) study, this was achieved by the correspondence between positive and negative shapes until the figure and ground became integrated. In Demirkan and Hasirci's (2009) study, the geometric relations of the elements and figure-ground relations were not considered, since they were not dominant in that specific artifact. Harmony was the most important characteristic in the assembly of design elements with the highest loading (0.891). In this study, the third factor consists of rhythm, repetition, unity and order as the assembly of design elements and number as the design element. In Demirkan and Hasirci's (2009) study, assembly of design elements was categorised in two parts as 'integrity' and 'in parts'. Rhythm was the third (0.841), unity was the fourth (0.831) in rank in 'integrity' subcategory. Repetition was the second $(0.805)$ in the 'in parts' subcategory. The exploratory maximum likelihood analysis helped to determine the relationship between creative design and design characteristics. This study supports the phenomenon that creativity is a natural component of design process.

\subsection{On the confirmatory factor analysis of design creativity}

The squared multiple correlation between the artifact creativity and the design elements was high (0.848) and also between the artifact creativity and the assembly of design elements (0.673). These findings comply with Hasirci and Demirkan's (2007) study where the product creativity was highly correlated (0.882) with the design elements and also with the assembly of design elements (0.848). The difference is that in their study each factor was tested independently.

\section{Conclusion}

The objective of this study was to develop an instrument for measuring the creativity of artifacts in design education. Creativity indicators as the items of the instrument were based on the review and appraisal of the literature on 
product/artifact creativity. This instrument was utilised for the assessment of 210 artifacts with satisfactory internal consistency. The results of factor analysis indicated a refined instrument with three factors (31 items).

The findings indicated that as the instructors examine a design artifact, novelty and affection characteristics provided by the design is the primary factor and it is associated with the shape of the design. As a second factor, the amount of elaboration presented in the artifact is important. The geometric relations of the elements and figure-ground relations both provide and increase in the elaboration characteristics of the artifact. Furthermore, harmony is a tool to assemble the design elements for elaboration of the artifact. In this factor, it is seen that elaboration is in interaction with design characteristics. Lastly, qualities of design as rhythm, repetition, unity and order affect the instructor. So, a creative design is a matter of the elaboration and design elements assembly together rather than novelty and affection alone. These three factors provide a theoretical and methodological framework for the development of tools that augment the designer on creative assessment.

Furthermore, the predictive validity of the assessment instrument was tested for each item. The corresponding values can be seen in detail in Table 4. Delighted in the artifact creativity, harmony in the assembly of design elements and shape in the design elements had the highest correlations. In addition, it was determined that the correlation between the artifact creativity and the design elements was high $(r=0.848)$ where there was a medium correlation $(r=0.673)$ between the artifact creativity and the assembly of design elements.

The three factor model was further tested for stability with the maximum likelihood confirmatory analysis and it was found that the model was fit. The confirmatory factor analysis helped to analyse each item in depth. The corresponding loadings of each item within each factor were identified. Originality in the artifact creativity, number in the design elements and rhythm in the assembly of design elements had the highest loadings in the structural equation model (Figure 3).

It is important to note that the factor loadings derived for the confirmatory factor analysis and the structural equation model are specific to the current sample and may partially have been impacted by the artifacts. This study is a pioneer in design education to the best knowledge of the authors. Therefore, it is expected the confirmatory factor analysis and the structural equation model's latent variables to operate in a similar fashion in other studies.

\section{Acknowledgements}

The authors would like to thank the first-year design students between 2006 and 2010 of the Department of Interior Architecture and Environmental Design at Bilkent University who contributed to this study with their designs. 


\section{References}

Akin, O., \& Akin, C. (1998). On the process of creativity in puzzles, inventions, and designs. Automation in Construction, 7(2-3), 123-138.

Arnheim, R. (1969). Visual thinking. London: Faber and Faber Limited.

Arnheim, R. (1977). The dynamics of architectural form. Berkeley/Los Angeles: University of California Press.

Bentler, P. M., \& Chou, C. P. (1987). Practical issues in SEM. Sociological Methods and Research, 16(1), 78-117.

Besemer, S. P. (1998). Creative product analysis matrix: testing the model structure and a comparison among products- three novel chairs. Creativity Research Journal, 11(4), 333-346.

Besemer, S. P., \& Treffinger, D. J. (1981). Analysis of creative products: review and synthesis. Journal of Creative Behavior, 15(3), 158-178.

Candy, L., \& Edmonds, E. (1996). Creative design of the Lotus bicycle: implications for knowledge support systems research. Design Studies, 17(1), 71-90.

Casakin, H., \& Kreitler, S. (2008). Correspondences and divergences between teachers and students in the evaluation of design creativity in the design studio. Environment and Planning B, 35(4), 666-678.

Ching, F. (2007). Architecture: Form, space, and order. New Jersey: John Wiley \& Sons.

Christiaans, H. H. C. M. (2002). Creativity as a design criterion. Creativity Research Journal, 14(1), 41-54.

Christiaans, H. H. C. M., \& Venselaar, K. (2005). Creativity in design engineering and the role of knowledge: modelling the expert. International Journal of Technology and Design Education, 15(3), 217-236.

Cross, N. (2002). Creative cognition in design: processes of exceptional designers. In T. Hewett, \& T. Kavanagh (Eds.), Creativity and cognition (pp. 14-19). New York: ACM Press.

Demirbas, O. O., \& Demirkan, H. (2003). Focus on architectural design process through learning styles. Design Studies, 24(5), 437-456.

Demirkan, H. (1998). Integration of reasoning systems in architectural modelling activities. Automation in Construction, 7(2-3), 229-236.

Demirkan, H. (2010). From theory to practice -39 opinions. In A. Williams, M. J. Ostwald, \& H. H. Askland (Eds.), Creativity, design and education. Theories positions and challenges (pp. 56-59). Sydney: ALTC.

Demirkan, H., \& Hasirci, D. (2009). Hidden dimensions of creativity elements in design process. Creativity Research Journal, 21(2-3), 294-301.

Dorst, K., \& Cross, N. (2001). Creativity in the design process: co-evolution of problem and solution. Design Studies, 22(5), 425-437.

Hasirci, D., \& Demirkan, H. (2003). Creativity in learning environments: the case of two sixth grade art-rooms. Journal of Creative Behavior, 37(1), 17-42.

Hasirci, D., \& Demirkan, H. (2007). Understanding the effects of cognition in creative decision-making: a creativity model for enhancing creativity in the design studio process. Creativity Research Journal, 19(2-3), 259-271.

Hatcher, L. (1996). Using SAS PROCALIS path analysis: an introduction. Structural Equation Modelling, 3(2), 176-192.

Hennessey, B. A. (1994). The consensual assessment technique: an examination of the relationship between ratings of product and process creativity. Creativity Research Journal, 7(2), 193-208.

Horn, D., \& Salvendy, G. (2006). Product creativity: conceptual model, measurement and characteristics. Theoretical Issues in Ergonomics Science, 7(4), $395-412$. 
Horn, D., \& Salvendy, G. (2009). Measuring consumer perception of product creativity: impact on satisfaction and purchasability. Human Factors and Ergonomics in Manufacturing, 19(3), 223-240.

Joreskog, K. G., \& Sorbom, D. (2011). LISREL 8.80. http://www.ssicentral.com/ lisrel/index.html.

Kreitler, S., \& Casakin, H. (2009). Self-perceived creativity: the perspective of design. European Journal of Psychological Assessment, 25(3), 194-203.

Kreitler, S., \& Casakin, H. (2010). Motivation for creativity in architectural design and engineering design students: implications for design. International Journal of Technology and Design Education, 20(4), 477-493.

Krueger, C., \& Cross, N. (2006). Solution driven versus problem driven design: strategies and outcomes. Design Studies, 27(5), 527-548.

Kunnan, A. J. (1998). An introduction to structural equation modeling for language assessment research. Language Testing, 15(3), 295-332.

Lawson, B. (1994). Design in mind. Oxford, UK: Butterworth Architecture.

Olgunturk, N., \& Demirkan, H. (2011). Colour and design: from natural patterns to monochrome compositions. Optics and Laser Technology, 43(2), 270-281.

O'Quin, K., \& Besemer, S. P. (1999). Creative products. In M. Runco, \& S. R. Pritzker (Eds.), Encyclopedia of creativity (pp. 413-422). Boston: Academic Press.

O'Quin, K., \& Besemer, S. P. (2006). Using the creative product semantic scale as a metric for results-oriented business. Creativity and Innovation Management, 15(1), 34-44.

Roy, R., \& Design Innovation Group. (1993). Case studies of creativity in innovative product development. Design Studies, 14(4), 423-443.

Runco, M. A. (2004). Creativity. Annual Review of Psychology, 55, 657-687.

Saris, W. E., Satorra, A., \& Sorbom, D. (1987). The detection and correction of specification errors in structural equation models. In C. Clogg (Ed.), Sociological methodology (pp. 105-129). San Francisco, CA: Jossey-Bass.

Shoukri, M. M., Asyali, M. H., \& Donner, A. (2004). Sample size requirements for the design of reliability study: review and new results. Statistical Methods in Medical Research, 13(4), 251-271.

Simonton, D. K. (2003). Scientific creativity as constrained stochastic behavior: the integration of product, person, and process perspectives. Psychological Bulletin, 129(4), 475-494.

Tabachnick, B. G., \& Fidell, L. S. (1996). Using multivariate statistics (3rd ed.). New York: HarperCollins.

Wallschlaeger, C., \& Busic-Snyder, C. (1992). Basic visual concepts and principles for artists, architects and designers. US: McGraw-Hill Inc. 